\title{
Posterior cervical fixation using a new polyaxial screw and rod system: technique and surgical results
}

\author{
Praveen V. Mummaneni, M.D., Regis W. Haid, M.D., Vincent C. Traynelis, M.D., \\ Rick C. Sasso, M.D., Brian R. Subach, M.D., Amory J. Fiore, M.D., \\ AND GERALD E. RODTS, M.D.
}

Department of Neurosurgery, Emory University, Atlanta, Georgia; Division of Neurosurgery, University of Iowa, Iowa City, Iowa; and Department of Orthopaedic Surgery, Indiana University School of Medicine, Indianapolis Neurosurgical Group, Indianapolis, Indiana

\begin{abstract}
Object. Standard lateral mass plate and screw systems are of limited use in patients with abnormal cervical anatomy and do not easily allow for extension to either the occipit or the thoracic spine. The objective of this study was to demonstrate the safety, surgical efficacy, and advantages of a new cervical polyaxial screw and rod system for posterior occipitocervicothoracic arthrodesis.

Methods. The authors reviewed a multicenter series of patients who underwent surgery in which they used a new posterior cervical polyaxial screw and rod system. The system was implanted in 32 (20 women and 12 men) adult patients (mean age 56.9 years, range 23-84 years). Twenty-three of the patients were treated for spondylostenosis; four for cervical fracture/dislocations; four for kyphosis; and one patient was treated for pseudarthrosis that developed after prior surgery.

The system was successfully implanted in all patients despite the presence of anatomical lateral mass anomalies in the majority of cases. The mean number of levels fused was 3.9 (range one-eight levels). This dynamic system allowed for screw placement into the occiput, C-1 lateral masses, C-2 pars, C3-7 lateral masses, and low cervical as well as upper thoracic pedicles. Selective application of compressive or distractive forces was possible in adjacent segments. Surgery-related complications included one dural tear and one malpositioned screw. There were two cases of wound infection.

Conclusions. Unlike standard lateral mass plate and screw systems, the new cervical polyaxial screw and rod system easily accommodates severe degenerative cervical spondylosis and curvatures. This instrumentation system allows for polyaxial screw placement with subsequent multiplanar rod contouring and offset attachment. The authors have used this system successfully, and without significant complications, to achieve posterior cervical arthrodesis.
\end{abstract}

KEY WoRDS • spinal fusion • cervical spine • lateral mass

Posterior cervical fixation in which lateral mass plates are placed has been shown to be a safe and efficacious method to achieve cervical fusion. ${ }^{1,2,5}$ Lateral mass plate systems are biomechanically superior to laminar wire or clamp fixation in limiting cervical motion. ${ }^{4,9,13,15}$ In addition, unlike posterior laminar wiring or clamping, lateral mass plating does not require the presence of the posterior elements.

Lateral mass plates, however, are not optimal for use in patients with cervical degenerative spondylosis-related abnormal curvatures because the plates are difficult to contour and the screw positions are dictated by the plate's entry holes. In addition, most of the systems currently available do not easily allow for extension of fusion up to the occiput or down to the thoracic spine. ${ }^{12}$

Other than the system that we used, there is one other commercially available system that does allow for initial screw placement with subsequent rod contouring. The

Abbreviation used in this paper: $\mathrm{CT}=$ computerized tomography.
Cervifix system (Synthes USA, Paoli, PA), however, does not have polyaxial screw heads and requires threading a contoured rod through closed-loop eye bolts, which can be difficult. ${ }^{10}$

One new polyaxial screw and rod system (Medtronic Sofamor Danek, Memphis, TN) addresses all of the limitations of the other systems currently available for posterior cervical arthrodesis. This system allows for initial screw placement as well as subsequent multiplanar rod contouring and attachment with or without offset connectors. The novel polyaxial cervical screw heads are especially useful for facilitating rod attachments in patients with severely abnormal cervical curvatures. In addition, the system is easily adaptable for occipital and thoracic extensions.

\section{CLINICAL MATERIAL AND METHODS}

\section{Patient Demographics}

Thirty-two patients treated at three centers underwent 
posterior cervical arthrodesis in which the cervical polyaxial screw and rod system was used. Twenty patients were women and 12 were men, and their mean age was 56.9 years (range 23-84 years).

Patients underwent preoperative CT scanning to delineate the osseous anatomy and the course of the vertebral arteries. Preoperative diagnoses included cervical spondylostenosis in 23, cervical fracture/dislocations in four (including one case of occipitocervical fracture/dislocation and one case of ankylosing spondylitis with a C-7 fracture), kyphosis in four, and pseudarthrosis from failed prior fusion in one patient (Table 1).

\section{Indications for Decompression and Fusion}

The indications for posterior cervical decompression and fusion are numerous. In cases of cervical fracture/ dislocations in which there is evidence of vertebral instability, the use of posterior instrumentation optimizes arthrodesis. In cases of pseudarthrosis, posterior cervical segmental instrumentation is useful to immobilize the segment and allow for fusion to occur.

In all of our 23 patients with spondylostenosis loss of normal cervical lordosis was observed. These patients all suffered cervical myelopathy or cervical radiculopathy in combination with severe degenerative changes. In the subset of these patients with cervical myelopathy requiring posterior decompression, it has been our practice to perform laminectomies combined with fusion if normal cervical lordosis is not evident. In patients with severe spondylotic radiculopathy in whom dynamic radiografts suggest segmental instability, it has also been our practice to perform posterior cervical decompression and stabilization. ${ }^{1,2}$

\section{Posterior Instrumentation}

The system consists of 6- to 10-mm titanium occipital screws and 14- to $18-\mathrm{mm}$ titanium polyaxial cervicothoracic screws. The system's titanium rods are malleable in three dimensions, and there is an available rod with an occipital plate on one end to allow for occipitocervical fusions.

When needed, the occipital screws must be placed through the apertures in the occipital plates. The polyaxial cervicothoracic screws, however, are placed independently of the rod system. The contoured rods are then linked either directly to the polyaxial screw heads by using a locking cap screw or are linked using an offset connector.

TABLE 1

Demographic data obtained in 32 patients

\begin{tabular}{lc}
\hline \hline Diagnosis & No. of Patients \\
\hline spondylostenosis & 23 \\
cervical fracture/dislocations & 4 \\
occipitocervical fracture/dislocation & 1 \\
ankylosing spondylitis & 1 \\
cervical kyphosis & 4 \\
pseudarthrosis & 1 \\
\hline
\end{tabular}

\section{SURGICAL TECHNIQUE}

A standard midline posterior cervical exposure was performed to reveal the lateral aspects of the cervical facets. The exposure was extended for one to two levels below the inferior end of the planned arthrodesis to allow for optimal screw placement. In patients with marked degenerative changes, the osteophytes on the posterior facets were removed to provide better visualization, to help define the anatomy of the facets, and to provide a suitable surface to allow for rotation of the polyaxial screw heads. We preserved, where possible, however, the posterior cortex of the articular mass to provide for better screw purchase. In the case of occipitocervical fusions, we exposed the suboccipital area up to the inion, and in that of cervicothoracic fusions, we also exposed the thoracic transverse processes.

In cases in which posterior decompression was necessary, we drilled and tapped pilot holes for the screws prior to performing laminectomies to preserve the normal anatomical landmarks for the screw trajectories. In addition, the lamina served to protect the neural elements during the preparation of screw holes. At C-7 and T-1, when decompression of the spinal canal was not necessary, at least minimal laminotomies were performed to expose the medial walls of the C-7 and T-1 pedicles prior to pedicle screw placement.

After the exposure was completed, we focused on cervical polyaxial screw placement. Initially, we used a highspeed drill to perforate the posterior cortices of the lateral masses. Our screw trajectories for C-3 to C-7 were based on prior guidelines (RW Haid, et al., unpublished data). Entry points were $1 \mathrm{~mm}$ medial to the center of the lateral mass, and trajectories were $20^{\circ}$ cephalad and 20 to $30^{\circ}$ lateral (Fig. 1). We "normalized" the entry point and screw trajectory at each lateral mass to allow for changes in the orientation of the lateral masses secondary to accentuated cervical lordosis or kyphosis and to allow for each patient's unique pathoanatomy. Because we did not routinely use fluoroscopy or image guidance (except when placing screws into $\mathrm{C}-1$ and $\mathrm{C}-2$ ), attention to the patient's unique cervical anatomy was of paramount importance.

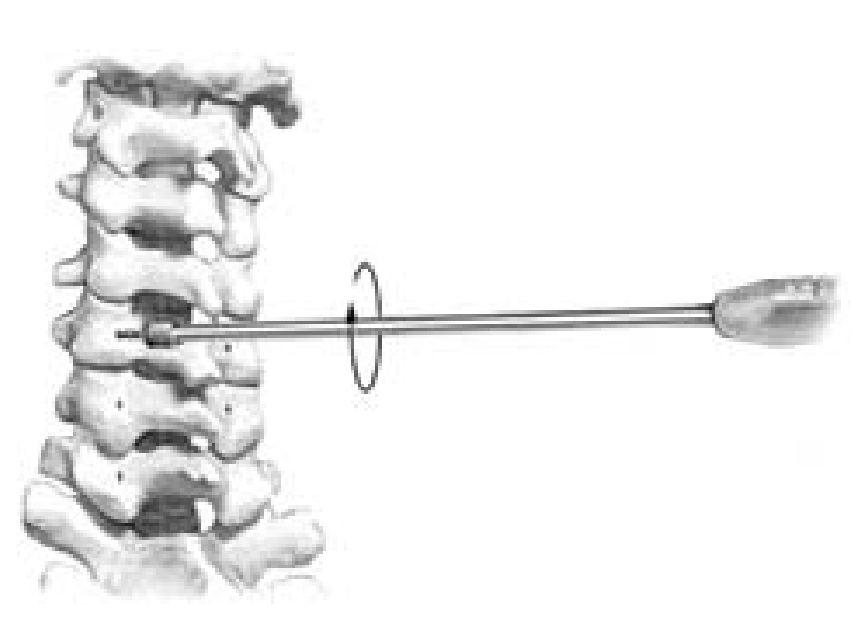

Fig. 1. Illustration showing that, after drilling and tapping, the polyaxial screw is inserted without the constraint of a lateral mass plate. 


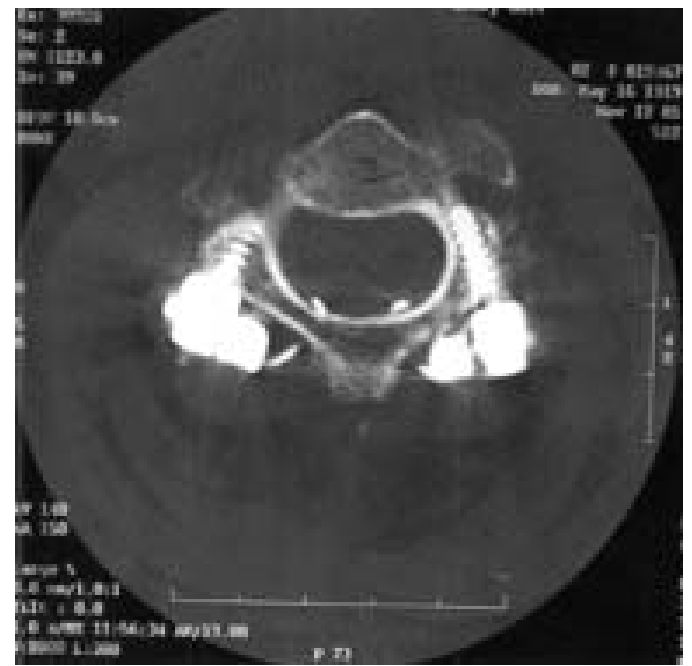

Fig. 2. Axial CT scan of $\mathrm{C}-2$ pars screw placement. Note the transverse foramen lateral to the tip of the screw, as well as the supplementation of sublaminar wire.

For screw placement into the lateral mass of C-1, we performed the technique described by Harms and Melcher ${ }^{8}$ and refined by Fiore, et al. ${ }^{3}$ The screw entry point was at the junction of the $\mathrm{C}-1$ posterior arch and the center of the $\mathrm{C}-1$ posteroinferior lateral mass. The screw trajectory was parallel to the plane of the C-1 lamina and was aimed straight anterior from the entry point.

For screw placement into the $\mathrm{C}-2$ pars, we paid close attention to the preoperative $\mathrm{CT}$ studies to assess the course of the vertebral artery. In addition, we used a blunt probe to palpate the medial pars to help guide our screw trajectory. We used a screw entry point 3 to $4 \mathrm{~mm}$ superior and lateral to the medial aspect of the $\mathrm{C} 2-3$ facet joint. The screw trajectory was 10 to $15^{\circ}$ medial and $35^{\circ}$ cephalad. We typically used 4-mm wide and $16-\mathrm{mm}$ long screws for the C-2 pars (Fig. 2). For C1-2 transarticular screw placement, the entry point and trajectory are the same as those for C-2 pars screws; the screw length, however, is longer. ${ }^{6,7}$

Screw placement at C-7 is dependent on the osseous anatomy. We scrutinized the preoperative CT scan to determine if the patient's C-7 lateral mass had typical cervical anatomy or had transitional thoracic anatomy with a well-formed pedicle. When the C-7 anatomy was transitional, we preferred to place a $\mathrm{C}-7$ pedicle screw.

For pedicle screw placement at C-7 or in the upper thoracic spine, we exposed and palpated the medial walls of the pedicles and utilized an entry point $1 \mathrm{~mm}$ below the center of the facet joint, and followed a trajectory 25 to $30^{\circ}$ medial while maintaining a perpendicular angle in the sagittal plane.

In the thoracic spine, pedicle screws can also be placed laterally into the costotransverse joint to achieve greater cortical purchase (Fig. 3). ${ }^{17}$

After polyaxial screw placement, the appropriate posterior decompressions were performed based on the patient's symptoms. In addition, the facet joints to be fused were stripped of cartilage and decorticated using a highspeed drill and then packed with autograft.

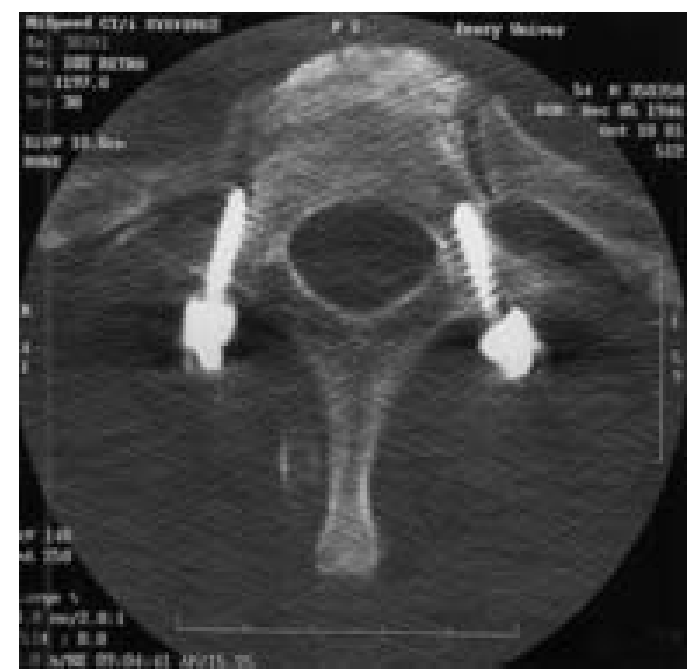

Fig. 3. Axial CT scan of T-1 pedicle screw placement. Note that the screw on the patient's right is inserted into the costotransverse joint and has increased cortical purchase.

The final step was to contour and attach the rods. A rod template was used to estimate the required rod-related length and contour (Fig. 4 left). The titanium rods were then measured, cut, contoured, and directly attached to the polyaxial screw heads by using locking cap screws (Fig. 4 right). In cases in which the patient's pathoanatomy required significantly different lateral or medial screw positions at successive levels, we used small offset connectors to facilitate rod attachment.

When occipitocervical fusions were planned, we used a specialized rod with an occipital plate attached at the cephalad end. Based on the rod trial, the rod and occipital plate were contoured and we positioned the occipital plate over the midline occipital keel to provide for the most bone purchase for the occipital screws. The occipital screws are not polyaxial and must be placed through the apertures in the occipital plates.

After the instrumentation was placed, but before final tightening of the construct, we compressed, distracted, or laterally rotated each successive segment as needed. We then packed autograft and occasionally bone extenders over the tops of the fusion sites.

\section{RESULTS}

Thirty-two patients underwent posterior cervical arthrodesis. Of these, 14 patients were treated by the Emory University group, 10 patients by the University of Iowa group, and eight patients by the Indianapolis group. The mean number of levels fused was 3.9 (range one-eight levels) (Table 2).

The dynamic properties of the polyaxial screw and rod system allowed for successful screw placement into the occiput (four patients; Fig. 5), C-1 lateral masses (one patient; Fig. 5), C-2 pars (four patients), C3-7 lateral masses (31 patients), and low cervical and upper thoracic pedicles (15 patients). In one patient occiput-T1 fusion was performed using a single construct. In one patient a supplemental C1-2 transarticular screw fixation was sup- 


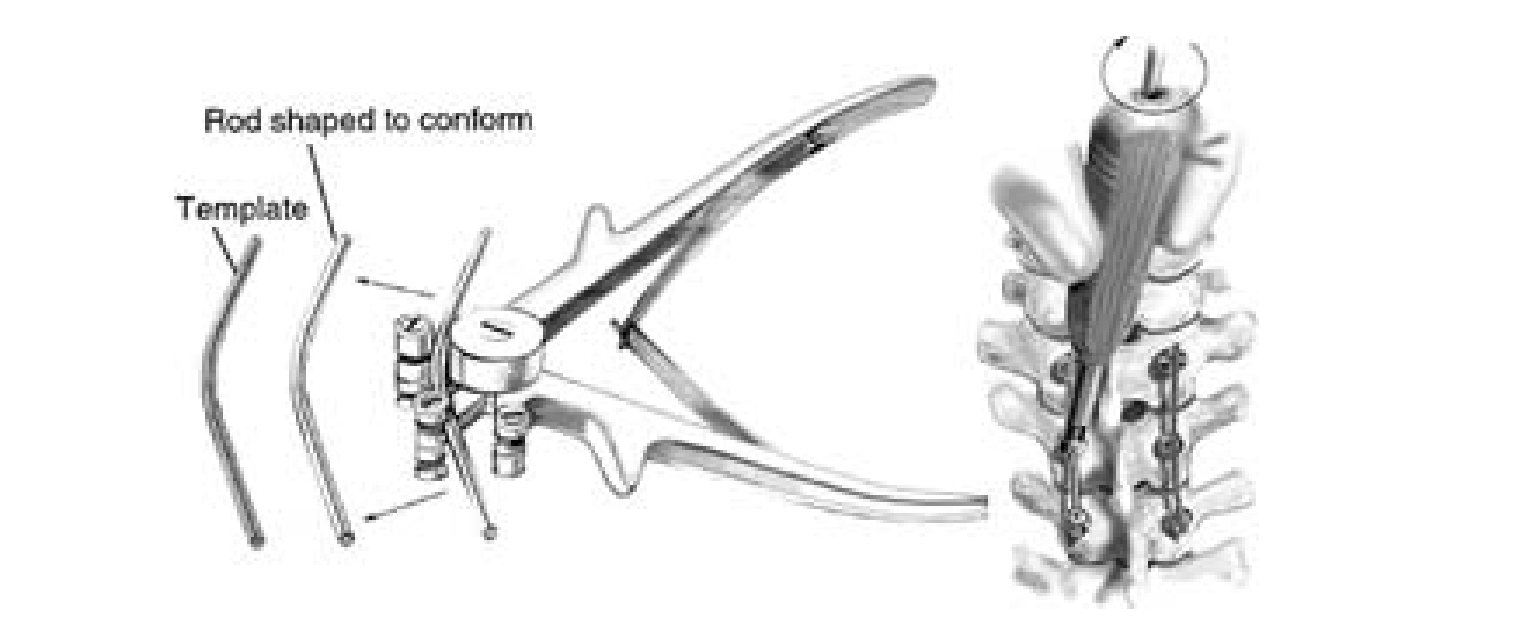

Fig. 4. Left: Illustration demonstrating the contouring of the multiplanar titanium rod based on the template. Right: Illustration demonstrating that the top-loading locking cap screw connects the polyaxial screw head to the rod.

plemented by placement of the posterior polyaxial system (Fig. 5). Six patients underwent supplemental anterior fixation (Fig. 6).

There were two surgery-related complications. In one patient, who had undergone prior cervical surgery, a dural tear occurred during decompression and was repaired primarily. Another patient, who was treated for a pseudarthrosis, suffered C-7 dysesthesias secondary to a malpositioned C-7 screw (Fig. 7). This patient was returned to surgery for screw revision, and his symptoms resolved thereafter.

\section{DISCUSSION}

Lateral mass plating has been shown to be an effective method of achieving posterior cervical arthrodesis and stabilization. ${ }^{5}$ Reported complication rates are low. Injury to the cervical spinal cord or vertebral artery have not

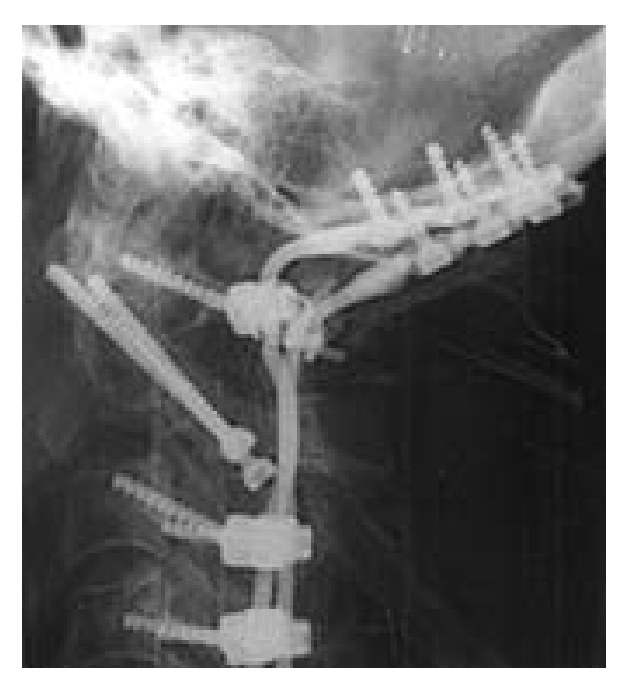

Fig. 5. Lateral radiograph demonstrating an occipitocervical fusion in which the extended-occipital-plate version of the cervical rod system has been used. Note the $\mathrm{C}-1$ lateral mass screw and the C1-2 transarticular screws. been reported in recent large published series on lateral mass plating. ${ }^{5,9,11,14,16}$ The rate of radiculopathy from malpositioned screws has ranged from 0 to $6 \%$ of patients. ${ }^{5,9,11,14,16}$

Lateral mass plates, however, are of limited use when fusion is performed from the occiput to the thoracic spine in patients with abnormal cervical anatomy because the system lacks malleability and predetermined screw hole trajectories. Although the Cervifix system overcomes some of these problems, it is suboptimal for cervicothoracic fusions because it requires connector devices at the cervicothoracic junction, which decreases the rigidity of the system. In addition, the Cervifix system requires threading of a contoured rod through closed loop eye bolts, which can be tedious and sometimes impossible. ${ }^{10}$

The new Medtronic posterior polyaxial cervical screw and rod system overcomes these problems because of its unique design. It has the versatility to accommodate oc-
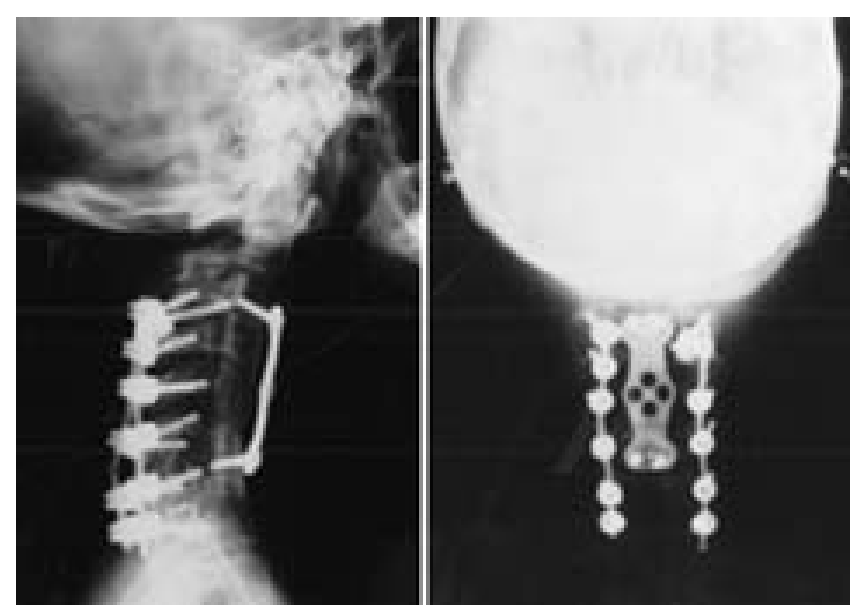

Fig. 6. Left: Lateral radiograph revealing the completed posterior polyaxial screw and rod construct with supplemental anterior decompression and fixation. Note the multiplanar rod contour. Right: Anteroposterior radiograph of same construct. Note the offset connector at the top of the construct. 


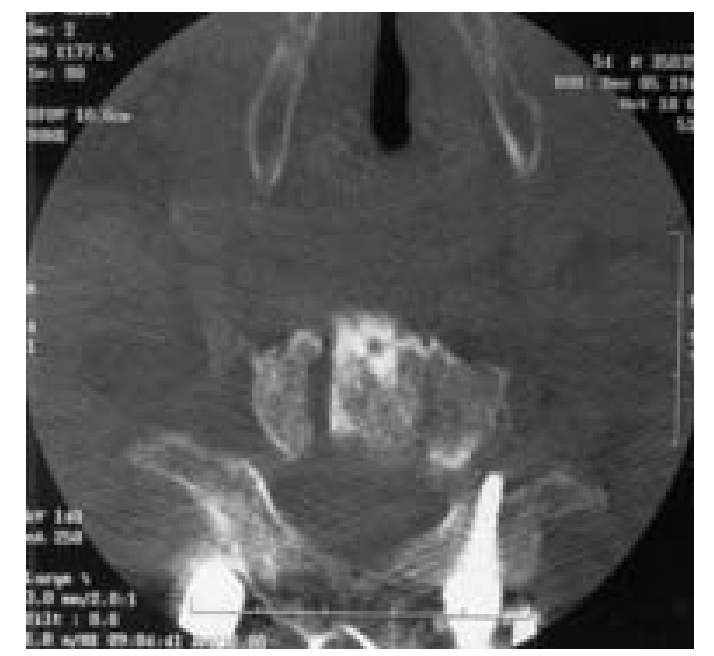

Fig. 7. Axial CT scan demonstrating a malpositioned C-7 screw impinging on the neural foramen.

cipitocervical fusions with $\mathrm{C}-1$ lateral mass screws, C-2 pars screws, or $\mathrm{C} 1-2$ transarticular screws. In addition, it allows for lateral mass fixation from C-3 to C-7 as well as pedicle fixation in the lower cervical and upper thoracic spine without the limitations inherent in placing screws through holes in lateral mass plates. Finally, the rods are easily attached either directly to the polyaxial screw heads or by using toploading offset connectors (Fig. 6 right).

We have successfully used this system in 32 patients to achieve posterior cervical arthrodesis, with minimal complications. Further studies will be required to establish long-term results and fusion rates.

\section{Acknowledgments}

The authors are grateful to Bill Winn for assistance with the illustrations. We are also grateful to Drew Imhulse and Tom Fletcher for assistance with the radiographic images in the figures.

\section{Disclosure}

The following authors are consultants for Medtronic Sofamor Danek: Regis W. Haid, Jr., M.D., Vincent C. Traynelis, M.D., Rick C. Sasso, M.D., Brian R. Subach, M.D., and Gerald E. Rodts, M.D.

\section{References}

1. Anderson PA, Henley MB, Grady MS, et al: Posterior cervical arthrodesis with AO reconstruction plates and bone graft. Spine 16 (Suppl 3):S72-S79, 1991

2. Fehlings MG, Cooper PR, Errico TJ: Posterior plates in the management of cervical instability: long-term results in 44 patients. J Neurosurg 81:341-349, 1994

3. Fiore AJ, Haid RW, Rodts GE, et al: Atlantal lateral mass screws for posterior spinal reconstruction: technical note and case series. Neurosurg Focus 12 (1): 1-Article 5, 2002

4. Gill K, Paschal S, Corin J, et al: Posterior plating of the cervical spine. A biomechanical comparison of different posterior fusion techniques. Spine 13:813-816, 1988

5. Graham AW, Swank ML, Kinard RE, et al: Posterior cervical arthrodesis and stabilization with a lateral mass plate. Clinical and computed tomographic evaluation of lateral mass screw placement and associated complications. Spine 21:323-329, 1996

6. Haid RW Jr: C1-C2 transarticular screw fixation: technical aspects. Neurosurgery 49:71-74, 2001

7. Haid RW Jr, Subach BR, McLaughlin MR, et al: C1-C2 transarticular screw fixation for atlantoaxial instability: a 6-year experience. Neurosurgery 49:65-70, 2001

8. Harms J, Melcher RP: Posterior C1-C2 fusion with polyaxial screw and rod fixation. Spine 26:2467-2471, 2001

9. Heller JG, Silcox DH III, Sutterlin CE III: Complications of posterior cervical plating. Spine 20:2442-2448, 1995

10. Horgan MA, Kellogg JX, Chesnut RM: Posterior cervical arthrodesis and stabilization: an early report using a novel lateral mass screw and rod technique. Neurosurgery 44: 1267-1272, 1999

11. Schultz KD Jr, McLaughlin MR, Haid RW Jr, et al: Singlestage anterior-posterior decompression and stabilization for complex cervical spine disorders. J Neurosurg 93 (Spine 2): 214-221, 2000

12. Smith MD, Anderson P, Grady MS: Occipitocervical arthrodesis using contoured plate fixation. An early report on a versatile fixation technique. Spine 18:1984-1990, 1993

13. Sutterlin CE III, McAfee PC, Warden KE, et al: A biomechanical evaluation of cervical spinal stabilization methods in a bovine model. Static and cyclical loading. Spine 13:795-802, 1988

14. Swank ML, Sutterlin CE III, Bossons CR, et al: Rigid internal fixation with lateral mass plates in multilevel anterior and posterior reconstruction of the cervical spine. Spine 22:274-282, 1997

15. Ulrich C, Woersdoerfer O, Kalff R, et al: Biomechanics of fixation systems to the cervical spine. Spine 16 (Suppl 3):S4-S9, 1991

16. Wellman BJ, Follett KA, Traynelis VC: Complications of posterior articular mass plate fixation of the subaxial cervical spine in 43 consecutive patients. Spine 23:193-200, 1998

17. Youkilis AS, Quint DJ, McGillicuddy JE, et al: Stereotactic navigation for placement of pedicle screws in the thoracic spine. Neurosurgery 48:771-779, 2001

Manuscript received November 26, 2001.

Accepted in final form December 19, 2001.

Address reprint requests to: Praveen V. Mummaneni, M.D., Department of Neurosurgery, The Emory Clinic, 1365 Clifton Road, Building B, Suite 6400, Atlanta, Georgia 30322. 